outcome of his labours. This has nearly 400 maps of about 500 taxa, and includes the critical genera Rubus (16 representative species), Alchemilla, Sorbus, Rhinanthus, Euphrasia and Hieracium, as well as species, subspecies, varieties and hybrids in various other genera. Each map, unlike those of the Atlas, is accompanied by brief notes in which the method of compilation of the map, the main sources of information, taxonomic criteria of the taxon and its ecology and distribution are given. The maps aro produced mainly from herbarium specimens which have been checked by experts, and are the same size as those of the Atlas.

There is much useful and interesting information in the notes, but I found several curiosities. Under Juniperus communis, for example, we are told that " . . . all records received for the species which occur outside the range of subsp. nana have been accepted as subsp. communis": this is surely begging the question. I got the impression, too, that the notes give more emphasis to European than to British ecology and distribution: to quote but one example, Minuartia recurva, discovered in the British Isles in 1964, "is found on the mountains of southern and southcentral Europe from Portugal to the south Carpathians", but its British station is not even mentioned.

Perhaps the worst error in the book is the map of Taraxacum palustre. This is reasonably plastered with dots, whereas it is fairly certain that there are not many more than a dozen sites for it in the British Isles. The mistake has presumably arisen because of confusion with the much commoner $T$. spectabile.

Besides the distribution maps and text there is a twopage introduction, a key to herbarium abbreviations, a bibliography and an index. Unfortunately there are none of the immensely valuable transparent overlay maps showing vice-counties, altitude, temperature, rainfall, and so on, with which the Atlas was supplied.

The book is an expensive one, but a pleasure to open. Anyone who found the Atlas interesting cannot help being stimulated by the Critical Supplement. Dr Perring is to be congratulated on another outstanding achievement.

A. R. Perry

\section{SPINNING AND DRAWING}

\section{Fiber Spinning and Drawing}

Edited by Myron J. Coplan. (American Chemical Society Symposium held at New York, September 13-15, 1966. Applied Polymer Symposia, No. 6.) Pp. vii + 183. (Interscience (Wiley): New York and London, 1967.) $56 s$.

THrs work forms the proceedings of a symposium arranged in 1966 jointly by the American Chemical Society Divisions of Polymer Chemistry and Cellulose, Wood, and Fiber Chemistry. Its eleven papers are mainly American in origin, but include two from Britain, one from the Netherlands, and one from Poland. It is likely to be an extremely valuable contribution to fibre science, as it is confined to filament extrusion and formation, a subject mainly treated in the patent literature which makes its logical appraisal somewhat difficult. This publication is encouraging, as although most of the contributors are from industry they approach the subject with a strongly academic bias, but with sufficient practical interest to show how much "know how" has still to be released in this field if the subject is to form a major aspect of polymer science.

About one-third of the papers deal with melt spinning, and tend to be biased to a theoretical mathematical approach, but they set out premises from which one might in due course be able to predict the behaviour of such materials of known constitutions in a spinning sequence. To summarize the papers in this field, they deal with the kinetics of polymer crystallization and orientation, the formation of the molten bulge at the spinning orifice, filament attenuation in melt spinning, and a calculation of filament temperature in melt spinning.

Unfortunately no papers are included on dry (evaporative) spinning and the comprehensive character of the publication suffers from this. On the other hand, the work contains six papers on wet spinning and a final paper in the broader field of the rate of formation of dislocations in drawing. This paper, which is a general review, brings into focus much work in the last decade which compares the deformation mechanism of polymers with those of dislocation, and so on, in conventional crystalline solids.

In the series on wet spinning, the extrusion problem is discussed, and also the morphology of rayon filament formation, diffusion as it affects coagulation, and a mechanical analysis of the wet spinning process. These form a most valuable physical contribution to the literature on wet spinning.

Two further papers complete the work, one on experimental studies of fibres from polymer solutions undergoing phase separation, and finally one on fibre formation by wet spinning and drawing of poly (bisbenzimidazobenzophenanthroline) which can retain approximately 50 per cent of the room temperature strength at $500^{\circ} \mathrm{C}$.

In such a review as this, it is impossible to detail the scope of the publication, but there is no doubt that it forms an important contribution to the fibre physics of the melt and wet spinning processes. The American Chemical Society is to be complimented on collecting together such a body of work, and above all in publishing in a field which in the past has been a comparatively closed subject.

F. HAPPEY

\section{EMF AND HIGH TEMPERATURES}

\section{Electromotive Force Measurements in High-Tempera- ture Systems}

Edited by C. B. Alcock. (Proceedings of a Symposium held by the Nuffield Research Group, Imperial College, London, April 13 and 14, 1967.) Pp. ix +227 . (Institution of Mining and Metallurgy: London, 1968.) $100 s$.

DURING the past forty years or so, use of the electromotive force (EMF) method as a means of investigating chemical equilibria has been extended to ever increasing tempera. tures - as have indeed most of the experimental thermochemical methods. 'This development is largely a result of the increasing interest in high-temperature materials and reactions.

In the case of the EMF method, this has implied a continuous search for suitable electrolytes which must be predominantly ionic conductors at the requisite temperature. Hence the development from aqueous solutions to molten chlorides, glass, solid oxides and molten fluorides! Solid oxide solutions, such as thoria-yttria and zirconia-calcia, remain predominantly oxygen-ion conductors well above $1,000^{\circ} \mathrm{C}$. The ranges of oxygen pressure in which ionic conductivity preponderates at these temperatures are still under investigation, but it is already clear that the EMF method employing solid-oxide or liquid-fluoride-electrolytes considerably extends the range of application of the existing methods for the measurement of free energies, in particular to oxide systems and alloy systems and, possibly, to metal carbides, nitrides and so on.

The time has come for an appraisal of our present state of knowledge-and it is fortunate that it was the Metallurgy Department of Imperial College that devoted its annual symposium to this topic because the department's experience in the field is second to none. The majority of the papers, on which extensive discussions were based, were presented by the hosts (C. B. Alcock, C. M. Diaz, A. D. Graves, D. Inman, J. H. E. Jeffes, Annemarie Kubik, F. D. Richardson, W. L. Roth, R. Sridhar, B, C. H Steele and Susan Zador). The distinguished visitors 